\title{
Marie-Chantal Killeen, En souffrance d'un corps. Essais sur la voix désincarnée
}

\section{Francesca Forcolin}

\section{Q OpenEdition}

1 Journals

\section{Edizione digitale}

URL: http://journals.openedition.org/studifrancesi/1682

DOI: 10.4000/studifrancesi. 1682

ISSN: 2421-5856

\section{Editore}

Rosenberg \& Sellier

\section{Edizione cartacea}

Data di pubblicazione: 1 novembre 2014

Paginazione: 656

ISSN: 0039-2944

\section{Notizia bibliografica digitale}

Francesca Forcolin, « Marie-Chantal Killeen, En souffrance d'un corps. Essais sur la voix désincarnée », Studi Francesi [Online], 174 (LVIII | III) | 2014, online dal 01 novembre 2014, consultato il 18 septembre 2020. URL : http://journals.openedition.org/studifrancesi/1682 ; DOI : https://doi.org/10.4000/ studifrancesi. 1682

Questo documento è stato generato automaticamente il 18 settembre 2020.

\section{(c)}

Studi Francesi è distribuita con Licenza Creative Commons Attribuzione - Non commerciale - Non opere derivate 4.0 Internazionale. 


\title{
Marie-Chantal Killeen, En souffrance d'un corps. Essais sur la voix désincarnée
}

\author{
Francesca Forcolin
}

\section{NOTIZIA}

MARIE-CHANTAL KILLEEN, En souffrance d'un corps. Essais sur la voix désincarnée, Editions Nota Bene, Canada, 2013, pp. 234

1 Nel film Farinelli del 1994, dedicato al celebre castrato Zambinella descritto da Balzac, Gérard Corbiau mette in scena una scissione radicale, quella tra corpo e voce. Un patto, infatti, unisce due fratelli che si spartiscono il compito della seduzione: uno ammalia le donne con la sua voce sublime, l'altro compie l'atto sessuale. La voce prelude al corpo, se ne allontana, si stacca, si scinde, ed è proprio questa désincarnation che permette alla voce di vivere di vita propria, nonché di far sentire il corpo attraverso se stessa. Voce che diviene oggetto, dunque: è questo il tema analizzato da Marie-Chantal KILLEEN nei 7 densi articoli proposti - voce provocante e provocatrice, voce scissa dal corpo, affascinante, divertente, angosciante, una voce off che proviene da un mondo altro, dall'oltretomba, una voce errante che un po' spaventa, un po' fa sognare. Una voce che seduce e rapisce, come quella grave e patetica di Tristan Vox nell'omonimo testo di Tournier, analizzato nell'ultimo capitolo a mo' di epilogo (Epilogue. Deux mots sur "Tristan Vox" (Tournier), pp. 209-217).

2 I testi analizzati dall'A., quasi tutti contemporanei, potrebbero essere suddivisi in tre parti. Nella prima, che comprende i primi due capitoli intitolati Feu le narrateur: $d u$ retour spectral au récit (Van Cauwelaert, Pennac), pp. 33-53, e Un narrateur sans organes: la voix off dans "Léolo" (Lauzon), pp. 55-74, vengono analizzati i romanzi Corps étranger di Van Cauwelaert, La petite marchande de prose di Pennac e il film Léolo di Lanzon del 1992. In queste opere troviamo istanze narrative improbabili, narratori d'oltretomba, 
apparizioni spettrali che compaiono sotto forma di voci spesso registrate: in ogni caso, si tratta di figure inadatte ad assumere l'enunciazione che viene loro attribuita. Nella seconda parte è invece questione di voce e genere: voci che con acrobazie lessicali non determinano mai la propria sessualità, voci né maschili né femminili, come accade in due testi di G. Rozier e A. Garréta, analizzati nel terzo articolo Sans genre ni corps: voix narratives dans "Un amour sans résistance" (Rozier) et "Sphinx" (Garréta), pp. 75-104. Voci che rimandano a un corpo senza ancoraggio sessuale, a un corpo ambiguo, una mescolanza dei generi intesa come trasgressione dei limiti come nel film Diva di J.-J. Beinex analizzato nel quarto articolo, "Diva" (Beineix), la voix enregistrée et la loi du genre (pp. 105-124).

Gli studi della terza parte analizzano opere scritte in prima persona. In "Larvatus prodeo": Roman Gary, "Pseudo" et l'art de la ventriloquie (pp. 125-140) l'analisi verte sulla ventriloquia nelle opere di Gary, dove la voce dello scrittore è talvolta espressa da altri strumenti o oggetti (bambole, ad esempio). Diversamente, invece, muovono testi quali L'amour, la fantasia di A. Djebar (in Qu'importe qui parle?: Assia Djebar, Gayatri Spivak et la politique de la voix, pp. 141-175), dove il dibattito sul femminismo e sul postcolonialismo è mosso da una voce solidamente ancorata in un corpo: una voce indigena autentica che coincide con un corpo preciso in un'opera che mescola la storiografia moderna con l'autobiografia. L'ultimo articolo è intitolato Toujours déjà désincarnée: Husserl, Joyce et les aventures derridiennes de la voix (pp. 178-207): alcuni testi di Husserl e di Joyce possono considerarsi fondatori del corpus derridiano, specialmente di opere quali La voix et le phenomène e Ulysse gramophone, poiché permettono all'autore di esplorare la problematica della voce, o meglio delle voci, non essendo questa mai univoca.

4 Per concludere, quelli analizzati dall'A. sono tutti testi legati dal fil rouge della ripetizione - ripetizione infinite volte della voce, grazie ai moderni strumenti di registrazione - ma soprattutto da un'ambivalenza nei confronti della voce senza corpo - un'oscillazione tra riconoscimento e sfiducia, consapevolezza e non della sua autonomia, perpetua tensione tra unione voce/corpo e sua scomposizione. 